\title{
PALINOFLORA DO ESTADO DO RIO GRANDE DO SUL, BRASIL: PHYTOLACCACEAE R. BR.
}

\author{
PAULO CÉSAR PEREIRA DAS NEVES, SORAIA GIRARDI BAUERMANN \\ Laboratório de Palinologia, ULBRA, Av. Farroupilha, 8.001, 92.425-900, Canoas, Brasil. \\ lab.palinologia@ulbra.br
}

ANA LUÍSA VIETTI BITENCOURT

Instituto Anchietano de Pesquisas, UNISINOS, Av. Brasil, 725, 93.001-970, São Leopoldo, Brasil.bitencourt@netu.unisinos.br

PAULO ALVES DE SOUZA

Laboratório de Palinologia, Departamento de Paleontologia e Estratigrafia, IG, UFRGS, Av. Bento Gonçalves, 9500, 91.540-000, Porto Alegre, Brasil.paulo.alves.souza@ufrgs.br

MARIA SALETE MARCHIORETTO

Instituto Anchietano de Pesquisas, UNISINOS, Av. Brasil, 725, 93.001-970, São Leopoldo, Brasil.herbariopaca@netu.unisinos.br

\section{SÉRGIO AUGUSTO DE LORETO BORDIGNON}

Laboratório de Palinologia, ULBRA, Av. Farroupilha, 8.001,92.425-900, Gravataí, Brasil.bordignon@ibest.com.br

\author{
JULIAN MAUHS \\ Instituto Anchietano de Pesquisas, UNISINOS, Av. Brasil, 725, 93.001-970, São Leopoldo, Brasil. \\ julianmauhs@bol.com.br
}

\begin{abstract}
RESUMO - O presente trabalho apresenta a descrição da morfologia polínica dos grãos de pólen de sete espécies, relativas a cinco gêneros da família Phytolaccaceae ocorrentes na flora do Estado do Rio Grande do Sul, Brasil (Microtea, Petiveria, Phytolacca, Rivina e Seguieria). Em termos botânicos, as espécies compreendem a plantas de hábito herbáceo a subarbustivo, raramente arbóreo, preferencialmente associadas a ambientes florestais. Do ponto de vista palinológico, a família é considerada euripolínica. Quatro tipos polínicos foram observados nas espécies analisadas: tricolpaldo (Phytolacca dioica, Phytolacca thyrsiflora, Seguieria langsdorffii e Seguieria aculeata), pantocolpado (Rivina humilis), pantoporado (Microtea scabrida) e estefanopontoperculado (Petiveria alliacea). Grãos de pólen de Seguieria aculeata são descritos pela primeira vez para o Estado do Rio Grande do Sul. Com base na configuração das aberturas e da escultura da exina, é apresentada uma identificação em nível de gênero. Foi comparada e discutida a morfologia polínica das espécies examinadas. Adicionalmente, similaridades puderam ser reconhecidas entre Microtea scabrida e Scabraperiporites nativensis, esta última espécie descrita para o Eoceno-Mioceno brasileiro como pertencente às Chenopodiaceae.
\end{abstract}

Palavras-chave: Phytolaccaceae, morfologia polínica, palinotaxonomia, Rio Grande do Sul.

ABSTRACT - PALYNOFLORA OF THE RIO GRANDE DO SUL STATE, BRAZIL: PHYTOLACCACEAE R. BR. The present paper presents the description of the morphological patterns of pollen grains of Microtea, Petiveria, Phytolacca, Rivina and Seguieria genera of the Phytolaccaceae family, occurring in the Rio Grande do Sul State, Southern Brazil. The habitus of these plants varies from since shrubs, sub-shrubs to rarely trees, mainly associated to the forestal environment. Four pollen types were recognized: 3-colpate (Phytolacca dioica, Phytolacca thyrsiflora, Seguieria langsdorffii, and Seguieria aculeata), pantocolpate (Rivina humilis), pantoporate (Microtea scabrida) and stephanopontoperculate (Petiveria alliacea). Pollen grains of Seguieria aculeata are described by the first time to the Rio Grande do Sul State. Identification of the genera based upon the aperture pattern and the sculpture of exine is presented. The pollen morphology of these species is compared and discussed. Additionally, similarities could be recognized between Microtea scabrida and Scabraperiporites nativensis, described for the Brazilian Eocene-Miocene as a Chenopodiaceae.

Key words: Phytolaccaceae, pollen morphology, palynotaxonomy, Rio Grande do Sul. 


\section{INTRODUÇÃO}

A circunscrição de Phytolaccaceae é controversa, sendo o número de gêneros e espécies variável conforme os diferentes sistemas de classificação (Englert \& Prantl, 1894; Cronquist, 1981; Judd et al., 2002; APG II, 2003). Cronquist (1981) considerou a família com 18 gêneros e 125 espécies e incluiu o gênero Microtea em Chenopodiaceae. Para Judd et al. (2002), Phytolaccaceae é constituída por quatro gêneros e 30 espécies, sendo o maior gênero Phytolacca (23 espécies). Segundo estes autores, os táxons que apresentam quatro tépalas, de quatro até numerosos estames, um só carpelo (com um único óvulo basal) e frutos do tipo drupa, aquênio, ou sâmara, podem ser mais bem separados como Petiveriaceae (Petiveria, Rivina e Trichostigma). Seguieria, que tem fruto do tipo sâmara, não é mencionada. Petiveriaceae também difere de Phytolaccaceae em caracteres embriológicos e na morfologia dos grãos de pólen. Tratamento diferente de Judd et al. (2002) é encontrado na APG II (2003), em que a família Petiveriaceae foi incluída em Phytolaccaceae. No presente trabalho, segue-se a sistemática proposta por Englert \& Prantl (1894).

A família Phytolaccaceae é pantropical e ocorre, principalmente, na América do Sul. No Brasil, está representada por nove gêneros (Barroso, 1978), dos quais cinco ocorrem no Rio Grande do Sul (Phytolacca, Microtea, Petiveria, Rivina e Seguieria). São plantas de hábito herbáceo a subarbustivo, raramente arbóreo, preferencialmente associadas a ambientes florestais. Segundo Judd et al. (2002), os representantes de Phytolaccaceae são tipicamente entomófilos (suas flores atraem abelhas, vespas, moscas e borboletas) e seus frutos são dispersos por pássaros.

A morfologia polínica das espécies de Phytolaccaceae estudadas é extremamente variável. A família é considerada euripolínica, compreendendo grãos de pólen desde tricolpados (Phytolacca e Seguieria), pantocolpados (Rivina) estefanopontoperculados (Petiveria) e pantoporados (Microtea).

Dentre os trabalhos de descrição polínica realizados para a família, destaca-se o de Erdtman (1952), que analisou 11 espécies de 10 gêneros encontrando morfologias polínicas variáveis desde tri e hexacolpados (colporoidados) a pantoporados.

Com base em material do Estado de Santa Catarina, Barth \& Barbosa (1972) apresentaram descrições completas para as espécies Phytolacca dioica, Phytolacca thyrsiflora, Seguieria glaziovii, Seguieria guaranitica, Microtea scabrida e Petiveria alliacea, incluindo ilustrações de microestruturas (cortes transversais da exina e ornamentação) e chave de identificação.

Bortenschlager (1973) descreveu a morfologia polínica de 16 gêneros da família, com base em material proveniente de diversas partes do mundo. Das espécies listadas, 24 ocorrem no Brasil, entre as quais, Phytolacca thyrsiflora, Seguieria langsdorffii e Rivina humilis, são também descritas no presente trabalho. Além disso, o autor listou Microtea scabrida e Seguieria paraguayensis (provenientes do
Paraguai), além de Petiveria alliacea (proveniente de Porto Rico). Roubik \& Moreno (1991) estudando a palinoflora da ilha de Barro Colorado, no Panamá, descreveram e organizaram uma chave polínica para Microtea debilis, Rivina humilis, Petiveria alliacea e Phytolacca rivinoides. Mais recentemente, Melhem et al. (2003) realizaram a descrição polínica de Phytolacca thyrsiflora, como grãos tricolpados, com base em material de Campos do Jordão, Estado de São Paulo, Brasil.

Este trabalho constitui uma contribuição ao conhecimento da diversidade polínica do Estado do Rio Grande do Sul. Apresenta uma comparação entre a morfologia polínica do material estudado e as informações disponíveis na literatura, discute as principais interpretações de classificação sistemática das Caryophyllales e correlaciona a morfologia polínica de Microtea scabrida ao registro paleontológico.

\section{MATERIAL E MÉTODOS}

O trabalho baseia-se em material proveniente, em sua maioria, de exsicatas do Herbarium Anchieta (PACA, Instituto Anchietano de Pesquisas, São Leopoldo, Rio Grande do Sul, Brasil), cuja coleção está organizada segundo o sistema de Engler \& Prantl (1894), que reúne, na família Phytolaccaceae, dentre outros, os gêneros Phytolacca (Phytolacca dioica e Phytolacca thyrsiflora), Microtea (Microtea scabrida), Petiveria (Petiveria alliacea), Rivina (Rivina humilis) e Seguieria (Seguieria langsdorffii e Seguieria aculeata).

O tratamento das amostras foi realizado segundo o método padrão de acetólise (Erdtman, 1952), no Laboratório de Palinologia da ULBRA, onde também foi realizada a análise polínica do material. Os grãos de pólen foram analisados em microscópio óptico LEICA LMB em 400 e 1.000x de aumento, com medidas realizadas em 25 grãos de pólen de cada espécie. A documentação fotomicrográfica e a comparação com táxons de registro fóssil foram efetuadas no Laboratório de Palinologia do Instituto de Geociências da UFRGS (IG/ UFRGS). Os espécimes ilustrados em microscopia óptica são provenientes de lâminas depositadas na Palinoteca do IG/ UFRGS. Lâminas de referência preparadas com gelatina glicerinada estão depositadas nas coleções de referência das três instituições envolvidas. Na preparação, para as análises de microscopia eletrônica de varredura, dos grãos de pólen de Petiveria alliacea, foi utilizado o método "Millonig isotonic" (Millonig, 1961), que consiste na lavagem dos grãos previamente acetolisados por três vezes, com a desidratação dos mesmos em uma bateria de acetona e centrifugação do sedimento em $2.800 \mathrm{rpm}$ por um tempo de 15 minutos. Após, o material foi metalizado em $\mathrm{Au} / \mathrm{Pd}$ com $15 \mathrm{~nm}$ de espessura e analisado em MEV XL20 (PHILIPS).

Informações sobre a distribuição geográfica das espécies foram consultadas em Marchioretto (1989), Marchioretto \& Siqueira (1993; 1998), Siqueira \& Marchioretto (1995) e Backes \& Irgang (2004). A base nomenclatural para os gêneros e espécies (Hooker \& Jackson, 1893) é apresentada no Apêndice. 


\section{DESCRIÇÕES}

\author{
Phytolacca dioica $\mathrm{L}$. \\ (Figuras 1A-E)
}

Descrição polínica. Grãos de pólen de tamanho médio, âmbito triangular, subprolatos, raramente prolatos, tricolpados, isopolares, radiossimétricos, eixo polar em torno de $31 \mu \mathrm{m}$ (28-32 $\mu \mathrm{m})$, eixo equatorial cerca de $23,5 \mu \mathrm{m}(23-25 \mu \mathrm{m})$, razão $\mathrm{P} / \mathrm{E} 1,3$; espessura da exina (no mesocolpo) $1,8 \mu \mathrm{m}$, tectados, columelados e punctado-espiculosos. Apocolpos com exina nitidamente mais espessada que nos mesocolpos, com báculos mais elevados nos apocolpos.

Material. Picada Verão, Sapiranga, RS: J. Mauhs \& C. F. Steffen, 07.09.1995 (Herbário PACA 74.459).

Características botânicas. Árvores de até $30 \mathrm{~m}$ de altura; floração entre agosto e novembro; frutificação entre novembro e fevereiro (Backes \& Irgang, 2004); habita freqüentemente orlas de matas, capões, capoeirões e campos cultivados.

Ocorrência. Distribui-se na América do Sul pela Argentina, Brasil, Equador, Paraguai e Uruguai. No Brasil, ocorre na Bahia, no Espírito Santo, no Rio de Janeiro, no Paraná, e em Mato Grosso, Mato Grosso do Sul, Minas Gerais, Santa Catarina e São Paulo. No Rio Grande do Sul, ocorre em todas as regiões do Estado (Marchioretto \& Siqueira, 1993).

\section{Phytolacca thyrsiflora Fenzl ex J.A. Schmidt} (Figuras 1F-I)

Descrição polínica. Grãos de pólen de tamanho médio, âmbito triangular, subprolatos a prolatos, tricolpados, isopolares, radiossimétricos, eixo polar em torno de 35,4 $\mu \mathrm{m}(29-42 \mu \mathrm{m})$, eixo equatorial cerca de $28,5 \mu \mathrm{m}(24-33 \mu \mathrm{m})$, razão P/E 1,24, espessura da exina (no mesocolpo) 2,0 $\mu \mathrm{m}$, tectados, columelados e punctado-espiculosos. Apocolpos com exina nitidamente mais espessada que nos mesocolpos, com báculos mais elevados nos apocolpos.

Material. Cinco Colônias, Canoas, RS: R. Záchia 574, 07.12.1991 (Herbário PACA- 74.186).

Características botânicas. Erva ou subarbusto de $50 \mathrm{~cm}$ a 3 $m$ de altura; floração entre agosto e janeiro; frutificação entre janeiro e maio; habita clareiras no interior das matas, ambientes degradados e declives com solos pedregosos.

Ocorrência. Distribui-se na porção insular da América Central (República Dominicana e Haiti) e na América do Sul (Brasil, Guiana Francesa, Paraguai e Peru). No Brasil, ocorre na Bahia, no Ceará, no Distrito Federal, no Espírito Santo, no Maranhão, no Pará, no Paraná, no Rio de Janeiro, e em Alagoas, Goiás, Mato Grosso, Mato Grosso do Sul, Minas Gerais, Pernambuco, Rondônia, Santa Catarina e São Paulo. No Rio Grande do Sul, somente não ocorre na região da Campanha (Marchioretto \& Siqueira, 1993).

\section{Microtea scabrida Urb.}

(Figuras 2A-C)

Descrição polínica. Grãos de pólen de tamanho pequeno, âmbito circular, esferoidais, pantoporados (mais de 20 poros), poros com diâmetro em torno de 2,0 $\mu \mathrm{m}(1,4-2,2 \mu \mathrm{m})$, apolares, radiossimétricos, diâmetro em torno de 22,2 $\mu \mathrm{m}(12-27 \mu \mathrm{m})$, espessura da exina $2,0 \mu \mathrm{m}$, tectados, columelados e microequinados.

Material. Iraí, RS: K. Emrich, 11.1949 (Herbário PACA48.169). Características botânicas. Erva ereta ou prostrada, de $20 \mathrm{~cm}$ a 1,5 m de altura; fenologia pouco conhecida para o Rio Grande do Sul (uma coleta com flor e fruto no mês de novembro); habita, preferencialmente, orlas e clareiras de matas.

Ocorrência. Distribui-se na América do Sul na Argentina, no Brasil, na Bolívia, no Paraguai, no Peru e no Uruguai. No Brasil, ocorre na Bahia, no Pará, no Paraná, no Rio de Janeiro, e em Minas Gerais, Pernambuco, Santa Catarina e São Paulo. No Rio Grande do Sul, ocorre na Depressão Central e na região das Missões (Marchioretto \& Siqueira, 1998).

\section{Petiveria alliacea $L$.}

(Figuras 2D,F e 3A,B)

Descrição polínica. Grãos de pólen de tamanho pequeno, âmbito circular, esferoidais com aspecto poligonóide, estefanopontoperculados com 6 pontopérculos, (delineáveis somente em MEV - Figuras 3A e 3B), apolares, radiossimétricos, diâmetro cerca de 24,8 $\mu \mathrm{m}(24-28 \mu \mathrm{m})$, espessura da exina $1,7 \mu \mathrm{m}$, tectados, columelados, micro reticulado-granulosos.

Material. Ad fl. Uruguay superius, Nonoai, RS: B. Rambo, 03.1945 (Herbário PACA 28.294).

Características botânicas. Subarbusto perene, ereto, até $1 \mathrm{~m}$ de altura; floração predominante entre novembro e março; frutificação entre abril e maio; habita locais sombrios, subúmidos, nas orlas e clareiras de matas; esporadicamente encontrada em Floresta Ombrófila Mista.

Ocorrência. Distribui-se nas Américas, desde a Flórida (Estados Unidos da América) até a Argentina, ocorrendo em todos os estados do Brasil. No Rio Grande do Sul, ocorre na Depressão Central, Encosta Inferior do Nordeste, Missões e Litoral (Marchioretto, 1989).

\section{Rivina humilis $\mathrm{L}$.}

(Figuras 1J-L)

Descrição polínica. Grãos de pólen de tamanho médio, âmbito circular, esferoidais com aspecto poligonóide, pantocolpados (quatro colpos), apolares, radiossimétricos, diâmetro equatorial cerca de $35,3 \mu \mathrm{m}(29-41 \mu \mathrm{m})$, espessura da exina 1,8 $\mu \mathrm{m}$, tectados, columelados e psilados.

Material. Lagoa da Porteira, Palmares do Sul, RS: J. Mauhs et al., 17.04.1997 (Herbário PACA 85.096).

Características botânicas. Erva ou subarbusto ereto, até cerca de $50 \mathrm{~cm}$ de altura; fenologia pouco conhecida para o Rio Grande do Sul (floração entre outubro e março, frutificação a partir de março até possivelmente julho); habita locais sombreados de matas, em barrancos altos próximos a rios e orla de matas. 

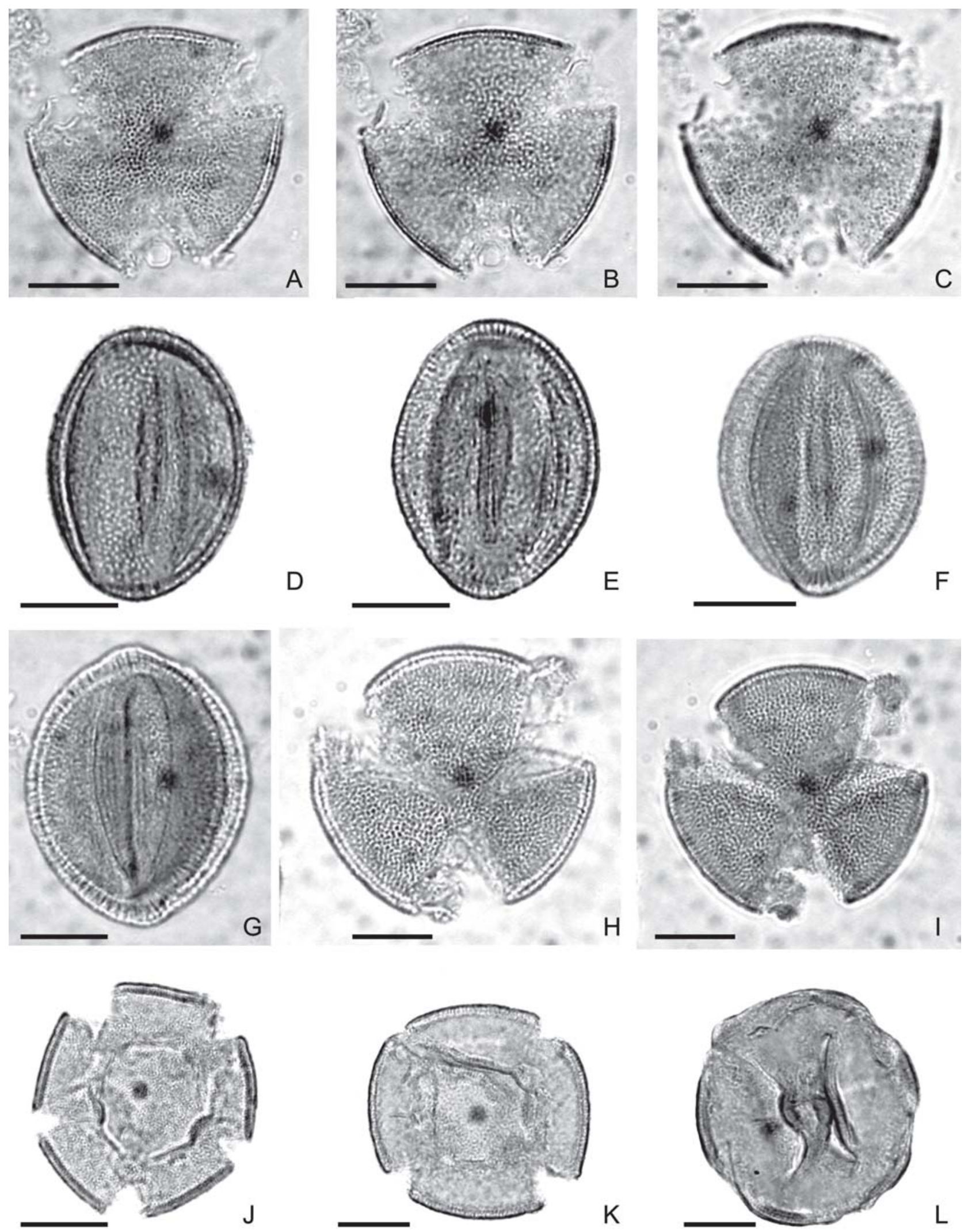

Figura 1. Fotomicrografias das espécies estudadas de Phytolaccaceae (lâminas e coordenadas England Finder são indicadas em parênteses): A-E, Phytolacca dioica (A-C: vista polar, P252-e, Q49; D: vista equatorial, P252-e, L51-3; E: vista polar, P252-e, Q48); F-I, Phytolacca thyrsiflora (F: vista equatorial, P257-e, F38; G: vista equatorial, P257-e, O39; H-I: vista polar, P257e, M38); J-L, Rivina humilis (J: P253e, K40; K: P253-e, N40-1; L: P253-e, P41). Escala = $10 \mu \mathrm{m}$.

Figure 1. Photomicrographs of selected species of Phytolaccaceae (slides and England Finder coordinates are in parenthesis): A-C, E, H-I, polar view; D, F, G, equatorial view. Scale bar $=10 \mu \mathrm{m}$. 
Ocorrência. Distribui-se nas Américas (desde o sudoeste dos Estados Unidos da América até a Argentina), na Ásia e na Oceania (Austrália). No Brasil, ocorre na Bahia, no Paraná, no Rio de Janeiro, e em Mato Grosso, Minas Gerais, Pernambuco (ilha de Fernando de Noronha) e São Paulo. No Rio Grande do Sul, ocorre no Litoral, na Depressão Central e no Planalto Médio (Siqueira \& Marchioretto, 1995).

\section{Seguieria aculeata Jacq.}

(Figuras 2G-I)

Descrição polínica. Grãos de pólen de tamanho médio, âmbito triangular, prolatos, tricolpados, isopolares, radiossimétricos, eixo polar em torno de $31,8 \mu \mathrm{m}(29-35 \mu \mathrm{m})$, eixo equatorial cerca de 21,5 $\mu \mathrm{m}(20-24 \mu \mathrm{m})$, razão P/E 1,48, espessura da exina 1,6 $\mu \mathrm{m}$, tectados, columelados e escabrados.

Material. Caraguatá, Cerro Largo, RS: A. Sehnem 15865, 15.02.1978 (Herbário PACA 82.061).

Características botânicas. Arbusto ou subarbusto escandente, até $10 \mathrm{~m}$ de altura; floração entre dezembro e março; frutificação entre março e junho; habita matas e orla das mesmas, esporadicamente em Floresta Ombrófila Mista. Ocorrência. Distribui-se na América Central (Panamá) e na América do Sul (Argentina, Brasil, Bolívia, Colômbia, Paraguai, Peru e Venezuela). No Brasil, ocorre no Amazonas, na Bahia, no Paraná, no Rio de Janeiro, e em Rondônia, Santa Catarina e São Paulo. No Rio Grande do Sul, ocorre em todas as regiões do Estado, exceto na Campanha (Siqueira \& Marchioretto, 1995).

\section{Seguieria langsdorffii Moq.}

(Figuras 2J-L)

Descrição polínica. Grãos de pólen de tamanho médio, âmbito triangular, subprolatos a prolatos, tricolpados, isopolares, radiossimétricos, eixo polar em torno de 30,8 $\mu \mathrm{m}(29-33 \mu \mathrm{m})$, eixo equatorial cerca de $23 \mu \mathrm{m}(22-26 \mu \mathrm{m})$, razão P/E 1,34, espessura da exina $1,5 \mu \mathrm{m}$, tectados, columelados e escabrados.

Quadro 1. Síntese das características diagnósticas diferenciais para os gêneros estudados de Phytolaccaceae do Rio Grande do Sul.

Chart 1. Summary of distinctive diagnostic features to the studied genera of Phytolaccaceae.

\begin{tabular}{|lc|}
\hline \multicolumn{1}{|c|}{ Morfologia polínica } & Gênero \\
\hline 1. Grãos de pólen tricolpados & \\
1a.exina com superfície punctado-espiculosa & Phytolacca \\
1b. exina com superfície escabrada & Seguieria \\
2. Grãos de pólen pantocolpados & Rivina \\
3. Grãos de pólen pantoporados & Microtea \\
4. Grãos de pólen estefanopontoperculados & Petiveria \\
\hline
\end{tabular}

Material. Fazenda do Capão, São Jerônimo, RS: O. Bueno 3.510, 27.04.1982 (HAS).

Características botânicas. Árvore com até $20 \mathrm{~m}$ de altura; fenologia pouco conhecida para o Rio Grande do Sul (uma coleta com flor e fruto no mês de abril); habita matas.

Ocorrência. Espécie exclusivamente brasileira, ocorrendo na Bahia, no Espírito Santo, no Paraná, no Rio de Janeiro, e em Minas Gerais, Santa Catarina e São Paulo. No Rio Grande do Sul, ocorre na Depressão Central (Siqueira \& Marchioretto, 1995).

\section{DISCUSSÃO}

A partir da análise das aberturas e da escultura da exina do material polínico estudado, estão sintetizadas as características diagnósticas diferenciais para os gêneros de Phytolaccaceae do Rio Grande do Sul (Quadro 1).

Em relação às Phytolaccaceae analisadas palinologicamente para o Estado do Rio Grande do Sul, novos dados são apresentados, por análise de microscopia eletrônica de varredura, para Petiveria alliacea, que apontou morfologia polínica com grãos de pólen estefanopontoperculados (Figuras 3A, B).

Barth \& Barbosa (1972), em estudos de morfologia polínica de Phytolaccaceae, consideram Petiveria alliacea como grãos pantoporados, sem, no entanto, apresentarem estudos em nível de microscopia eletrônica. Somente por análise de microscopia óptica (Figuras 2D, F) não é possível determinar o tipo de abertura da espécie. Dessa forma, a análise sob microscopia eletrônica de varredura (Figuras 3A-B) atestou abertura estefanopontoperculada para estes grãos.

Como pode ser observado na literatura, existem diferentes interpretações entre os autores, em relação às aberturas do pólen de Phytolaccaceae, bem como quanto à sua delimitação. O sistema proposto por Cronquist (1981), que retirou o gênero Microtea de Phytolaccaceae, está de acordo com as análises palinológicas, pois Microtea scabrida é a única representante com tipo polínico pantoporado. Pela morfologia polínica, esta espécie estaria incluída na família Chenopodiaceae conforme sugerido pelo autor.

A família Petiveriaceae, proposta por Judd et al. (2002), inclui, dentre os táxons aqui analisados, Petiveria e Rivina, os quais exibem morfologias polínicas diferentes, estefanopontoperculado e pantocolpado, respectivamente. Segundo esses autores, Phytolaccaceae teria sua delimitação restrita aos grãos de pólen tricolpados, constituindo, então, um clado monofilético. Phytolaccaceae pertence à ordem Caryophyllales, que tem como característica polínica a presença de grãos colpados (APG II, 2003). Considerando esta característica, Petiveria alliacea (estefanopontoperculado) e Microtea scabrida (pantoporado) não estão adequadamente abrigadas naquela ordem. Este sistema de classificação também considera Phytolaccaceae (incluindo Petiveriaceae e excluindo Microtea, que foi transferida para Amaranthaceae) distribuída em três subfamílias: Phytolaccoideae, Rivinoideae e Agdestidoideae. À subfamília Phytolaccoideae pertence o 

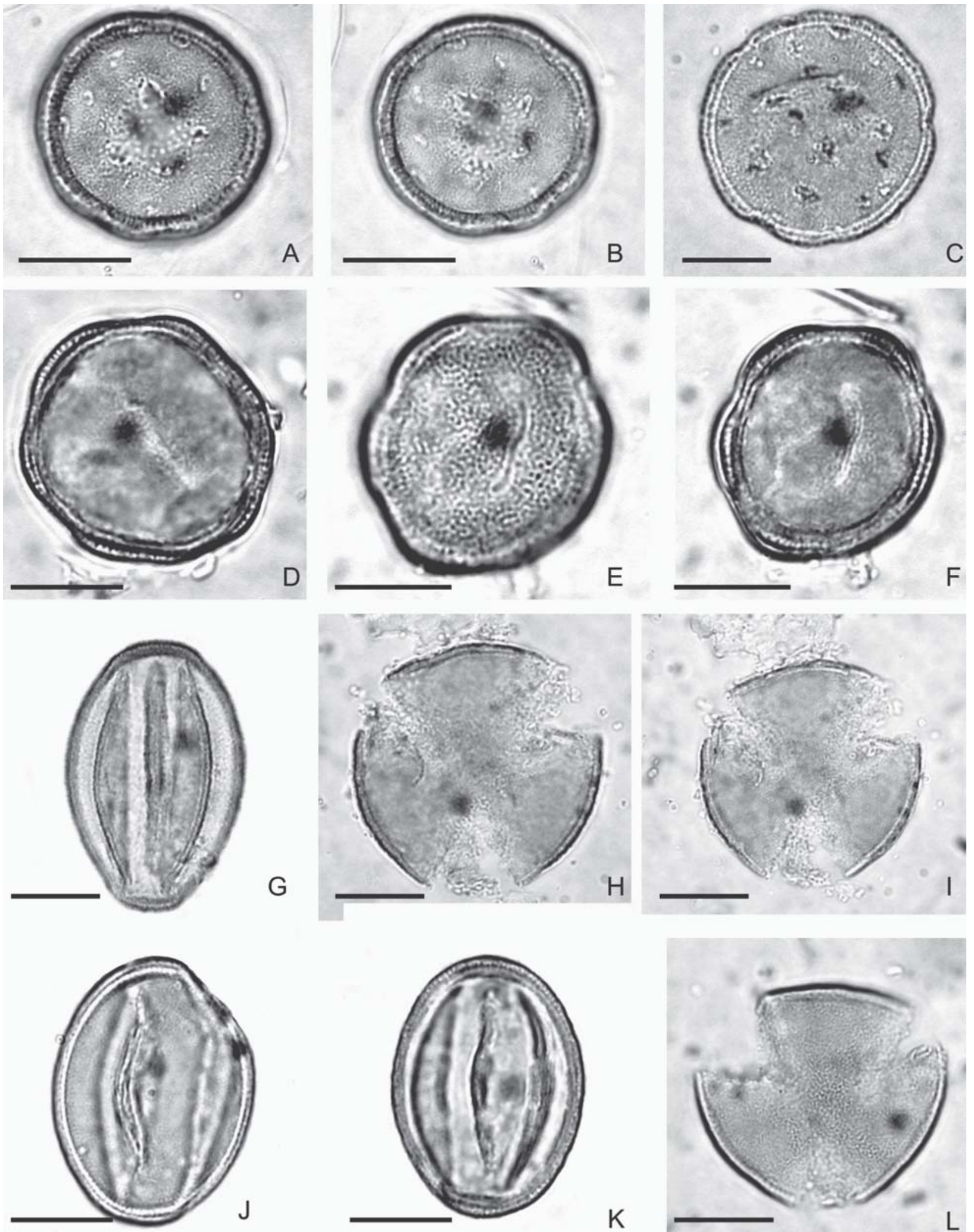

Figura 2. Fotomicrografias das espécies estudadas de Phytolaccaceae (lâminas e coordenadas England Finder são indicadas em parênteses): A-C, Microtea scabrida (A-B: P256-e, P37-4; C: P256-e, N47); D-F, Petiveria alliacea (D: P254-e, K45; E-F: P254-e, N43); GI, Seguieria aculeata (G: vista equatorial, P255-e, H43-3; H-I: vista polar, P255-e, J42); J-L, Seguieria langsdorfii (J: vista equatorial, P251e, R41-3; K: vista equatorial, P251-e, S42-1; L: vista polar, P251-e, P45-2). Escala = $10 \mu \mathrm{m}$.

Figure 3. Photomicrographies of selected species of Phytolaccaceae (slides and England Finder coordinates are in parenthesis): G, J, K, equatorial view; H-I, polar view. Scale bar $=10 \mu \mathrm{m}$. 
gênero Phytolacca (tricolpado). Em Rivinoideae, estariam os gêneros Rivina, Petiveria e Seguieria, os quais possuem tipos de abertura diferentes. Além disso, neste sistema de classificação, Petiveria é considerada como pantoporada, característica observada apenas por Barth \& Barbosa (1972) para o gênero.

Estudos de filogenia molecular realizados em Caryophyllales por Cuénoud et al. (2002) mostraram que as três subfamílias de Phytolaccaceae não parecem estar relacionadas entre si. A subfamília Rivinoideae (representada por Gallesia, Hilleria, Ledenbergia, Petiveria, Rivina e Seguieria) formou um grupo monofilético mais intimamente relacionado às Nyctaginaceae do que às Phytolaccaceae, e o gênero Microtea (conforme citações em Cuénoud et al., 2002), tem afinidade sugerida à família Chenopodiaceae, corroborando Cronquist (1981).

Por outro lado, ao se relacionar o hábito das plantas com o tipo apertural do pólen das mesmas, observa-se que as
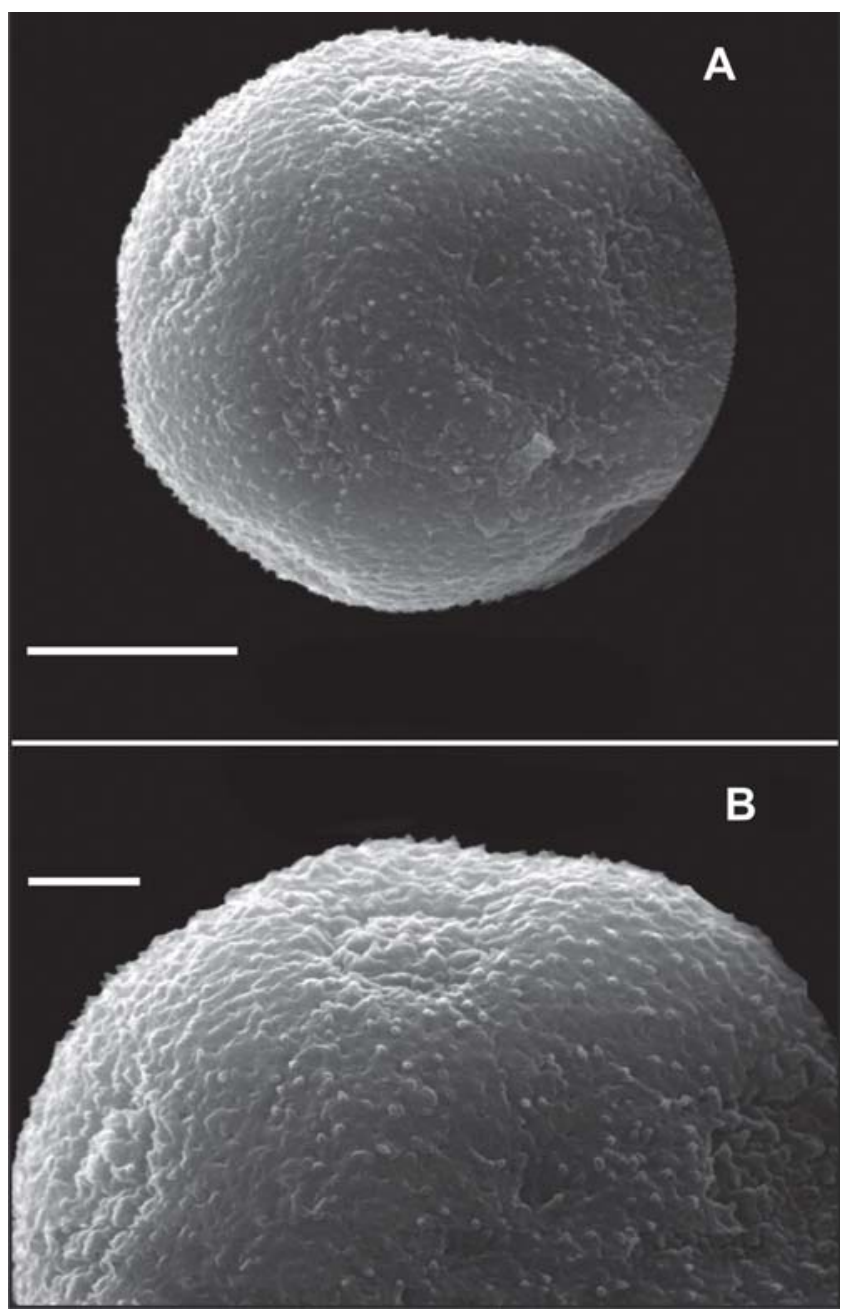

Figura 3. Fotografias (MEV) de Petiveria alliacea: A, vista geral do grão; $\mathbf{B}$, detalhe das zonas de abertura. Escalas: $\mathbf{A}=5 \mu \mathrm{m}$; $B=2 \mu \mathrm{m}$.

Figure 3. SEM photographs of Petiveria alliacea: A, general view; B, detail on aperture zone. Scale bars: $\mathbf{A}=5 \mu \mathrm{m} ; \mathbf{B}=2 \mu \mathrm{m}$. espécies arbóreas e/ou subarbustivas (Phytolacca dioica, Phytolacca thyrsiflora, Seguieria langsdorffii e Seguieria aculeata) são tricolpadas. Petiveria alliacea, embora subarbustiva, tem tipo morfológico estefanopontoperculado. Dentre as espécies subarbustivas/herbáceas, Rivina humilis é pantocolpada e Microtea scabrida, de hábito herbáceo, apresenta morfologia polínica do tipo pantoporado.

$\mathrm{O}$ registro paleopalinológico indica que, ao longo do tempo geológico, de maneira geral, os pólens das angiospermas tiveram seu número de aberturas aumentado variando desde inaperturados, monoaperturados, triaperturados, registrados em estratos do Cretáceo, a multiporados a partir do Terciário (Pflug, 1953; Jarzen \& Nichols, 1996).

Considerando a morfologia polínica com poucas aberturas e plantas de hábito arbóreo como características basais para as angiospermas, as espécies analisadas aqui parecem refletir a evolução do grupo no sentido árvores/subarbustos com presença de três colpos; subarbustos/ervas com aberturas variando de pantocolpadas a estefanopontoperculada e as ervas com tipo morfológico pantoporado. Interpretações similares já foram preconizadas por Barth \& Barbosa (1972) e Bortenschlager (1973).

Das espécies de Phytolaccaceae estudadas, a maior similaridade, em relação ao pólen de plantas do registro fossilífero, foi verificada entre as espécies Microtea scabrida e Scabraperiporites nativensis. Esta última espécie foi descrita para a plataforma continental brasileira (Regali et al., 1974), exceto bacia de Pelotas, com distribuição entre o Eoceno Médio e o Oligoceno, tendo sido atribuída à família Chenopodiaceae (cuja circunscrição inicial incluía Phytolaccaceae). Scabraperiporites nativensis também foi registrado, posteriormente, nos Andes bolivianos, em estratos de idade eocênica-oligocênica (Horton et al., 2001).

Portanto, a variada morfologia polínica da família Phytolaccaceae, provavelmente relacionada à sua origem polifilética, atesta seu caráter euripolínico bem como reflete a relação filogenética complexa existente entre os táxons das Caryophyllales.

\section{AGRADECIMENTOS}

Os autores agradecem à Marleni Marques-Toigo (in memoriam) pelo apoio e incremento dado à palinologia de Quaternário no estado do Rio Grande do Sul e, particularmente, como incentivadora na formação deste grupo de pesquisa; Pedro Ignácio Schmitz S.J., Diretor do Instituto Anchietano de Pesquisas, por apoiar e possibilitar o acesso à coleção de plantas do Herbarium Anchieta (PACA), como principal fonte de material para o desenvolvimento do projeto; e a Ortrud Monika Barth e Luisa Matilde Anzótegui pelas sugestões apresentadas como revisoras do trabalho. Este estudo é parte inicial do projeto "Coleção de grãos de pólen de referência de plantas do sul do Brasil", em desenvolvimento a partir de convênio interinstitucional entre o Instituto Anchietano de Pesquisas (UNISINOS), e os Laboratórios de Palinologia da ULBRA e do Instituto de 
Geociências da UFRGS, cujo principal objetivo é a caracterização da morfologia polínica de espécies vegetais do Rio Grande do Sul, visando fornecer subsídios para a identificação de grãos de pólen em estudos palinológicos de caráter paleoambiental, paleoclimático, estratigráfico e taxonômico.

\section{REFERÊNCIAS}

APG II. 2003. An update of the Angiosperm Phylogeny Group Classification for the orders and families of flowering plants: APG II. Botanical Journal of Linnean Society, 141:399-436.

Backes, P. \& Irgang, B. 2004. Mata Atlântica - as árvores e a paisagem. Porto Alegre, Editora Paisagem do Sul, 393 p.

Barroso, G.M. 1978. Sistemática de Angiospermas do Brasil. São Paulo, Editora da Universidade de São Paulo, 255 p.

Barth, O.M. \& Barbosa, A.F. 1972. Catálogo sistemático dos pólens das plantas arbóreas do Brasil Meridional. XIV Nytaginaceae e Phytolaccaccea. Memórias do Instituto Oswaldo Cruz, 70(3):241-267.

Bortenschlager, S. 1973. Morphologie pollinique des Phytolaccaceae. Pollen et Spores, 15(2):227-253.

Cronquist, A. 1981. An integrated system of classification of flowering plants. New York, Columbia University Press, $1262 \mathrm{p}$.

Cuénoud, P.; Savolainen, V.; Chatrou, L.W.; Powell, M.; Grayer, R.J. \& Chase, M.W. 2002. Molecular phylogenetics of Caryophyllales based on nuclear 18S rDNA and plastid rbcL, atpB and matK DNA sequences. American Journal of Botany, 89:132-144.

Engler, A. \& Prantl, K. 1894. Die Natürlichen Pflanzenfamilien. Leipzig, Wilhen Engelmann, v. III(1b), 14 p.

Erdtman, G. 1952. Pollen morphology and plant taxonomy. Stockolm, Almkvist \& Wiksell, 539 p.

Hooker, J.D. \& Jackson, B.D. 1893. Index kewensis; an enumeration of the genera and species of flowering plants. Oxford, Claredon Press., v. I-II.

Horton, B.K.; Hampton, B.A. \& Waanders, G.L. 2001. Paleogene synorogenic sedimentation. Society of America Bulletin, 113(11):1387-1400.

Jarzen, D.M. \& Nichols, D.J. 1996. Pollen. In: J. Jansonius \& D.C. McGregor (eds.) Palynology: principles and applications. American Association of Stratigraphic Palynologists Foundation, v. 1, p. 261-292.

Judd, W.; Campbell, C.S.; Kellog, E.A.; Stevens, P.F. \& Donogahue, M.J. 2002. Plant Systematic: a phylogenetic approach. 2 ed., New York, Sinauer, 576 p.

Marchioretto, M.S. 1989. A família Phytolaccaceae no Rio Grande do Sul. Pesquisas, Botânica, 40:5-67.

Marchioretto, M.S. \& Siqueira, J.C. 1993. O gênero Phytolacca L. (Phytolaccaceae) no Brasil. Pesquisas, Botânica, 44:5-40.
Marchioretto, M.S. \& Siqueira, J.C. 1998. O gênero Microtea Sw. (Phytolaccaceae) no Brasil. Pesquisas, Botânica, 48:5-51.

Melhem, T.S.; Cruz-Barros, M.A.V.; Corrêa, A.M.S.; MakinoWatanabe, H.; Silvestre-Capelato, M.S.F. \& Esteves, V.L.G. 2003. Variabilidade polínica em plantas de Campos de Jordão (São Paulo, Brasil). Instituto de Botânica, 104 p. (Boletim 16).

Millonig, G. 1961. Advantages of a phosphate butter of OsO solutions in fixation. Journal of Aplicattion Physics, 32(8):1837.

Pflug, H.D. 1953. Zur Entstehung und Entwicklung des angiospermiden Pollens in der Erdgeschichte. Palaeontographica, Abt. B, 95:60-171.

Regali, M.S.P.; Uesugui, N. \& Santos, A.S. 1974. Palinologia dos sedimentos meso-cenozóicos do Brasil (I). Boletim Técnico da Petrobrás, 17(4):263-301.

Roubik, D.W. \& Moreno, J.E.P. 1991. Pollen and spores of Barro Colorado Island. Monographs in systematic botany from the Missouri Botanical Garden, 36:1-300.

Siqueira, J.C. \& Marchioretto, M.S. 1995. Padrões de distribuição geográfica da família Phytolaccaceae no Brasil. Pesquisas, Botânica, 45:23-62.

Received in January, 2006; accepted in March, 2006.

Apêndice. Relação dos gêneros e espécies citados no texto. Appendix. List of genera and species cited in the text.

Gallesia Casaretto

Hilleria Vell.

Ledenbergia Klotzsch ex Miq

Microtea Sw.

Microtea debilis Sw.

Microtea scabrida Urb.

Petiveria L.

Petiveria alliacea L.

Phytolacca L.

Phytolacca dioica L.

Phytolacca rivinoides Kunth \& Bouché

Phytolacca thyrsiflora Fenzl ex J. A. Schmidt

Rivina L.

Rivina humilis L.

Scabraperiporites nativensis Regali, Uesugui \& Santos 1974

Seguieria Löefling

Seguieria aculeata Jacq.

Seguieria glaziovii Briq.

Seguieria guaranitica Speg.

Seguieria langsdorffii Moq.

Seguieria paraguayensis Morong.

Trichostigma A. Rich.

Trychostigma octandrum (L.) H. Walter 